\title{
Canadian Public Health Laboratory Network national syphilis laboratory testing recommendations
}

\author{
June 2014; Revised September 2014 \\ Members of the Canadian Public Health Laboratory Network Syphilis Laboratory Task Group during authorship \\ (co-chairs and membership in alphabetical order):
Raymond SW Tsang PhD (Federal Co-Chair) ${ }^{1}$, Muhammad Morshed PhD SCCM (Provincial Co-Chair) ${ }^{2}$, Vanessa Allen MD ${ }^{3}$, Max A Chernesky PhD FIDSA FAAM FCCM ${ }^{4}$, Kevin Fonseca PhD D(ABMM) ${ }^{5}$, Richard Garceau MD FRCPC ${ }^{6}$, Gayatri C Jayaraman PhD MPH ${ }^{7}$, Kamran Kadkhoda PhD FCCM ${ }^{8}$, Bonita E Lee MD FRCPC MSc ${ }^{9}$, Paul N Levett DSC (D)ABMM FCCM FAAM ${ }^{10}$, Sandra M Radons BSc ${ }^{11}$, Bouchra Serhir MSc PhD ${ }^{12}$, Ameeta E Singh BMBS MSc FRCPC ${ }^{13}$, Tom Wong MD MPH CCFP FRCPC ${ }^{14}$

\section{INTRODUCTION}

\section{PROCESS STATEMENT}

The development of these recommendations arose in the spring of 2009 under the support and recommendation of the Canadian Public Health Laboratory Network (CPHLN). The initial group was formed of a federal co-chair (RT), a provincial co-chair (MM) and a CPHLN secretariat lead (SR). An initial environmental scan was performed in 2009, which was published in August 2011 (R Tsang, SM Radons, M Morshed. Laboratory diagnosis of syphilis: A survey to examine the range of tests used in Canada. Can J Infect Dis Med Microbiol 2011;22[3]:83-87). National representation was added to the working group in 2010, including laboratory scientists from the provincial public health laboratories, STI clinicians, epidemiologists and researchers. The group divided into smaller groups for the drafting of each chapter, which was written and presented back to the larger group. Once the document was finalized by the Syphilis Working Group, it was reviewed and approved by the CPHLN Laboratory Directors Council (comprised of federal/provincial/territorial PHL directors or their representatives), before submission to the Journal.

\section{TREPONEMA PALLIDUM AND RELATED AGENTS}

Syphilis is caused by the spirochaete, Treponema pallidum subsp. pallidum. The spiral-shaped bacteria is related to other species causing non-venereal diseases including Treponema pertenue, which causes yaws; Treponema endemicum, which causes endemic syphilis (bejel); and Treponema carateum, which causes pinta (1). There is a high degree of antigenic relatedness among the pathogenic treponemes $(2,3)$. Available serological tests for syphilis are reactive in persons infected with any of the treponematoses, but none of these tests can distinguish endemic treponemal infections from venereal syphilis $(2,3)$. Currently, therefore, they are indistinguishable by morphological, immunological or serological methods $(2,3)$. Although several minor genetic differences have been identified among the subspecies, the means to distinguish between these species remain limited $(2,3)$.
It is noteworthy, however, that a recent case report from Canada described the use of genomic techniques to demonstrate transmission of endemic syphilis in Canada (4).

\section{TRANSMISSION, PATHOGENESIS AND CLINICAL MANIFESTATIONS OF SYPHILIS}

T. pallidum is an obligate human parasite with no known reservoirs in animals or in the environment. Most cases of venereal syphilis occur due to direct sexual contact with lesions containing the bacteria. Studies of sexual partners of patients with syphilis report a risk of infection to approximately one-third (10\% to 60\%) of patients exposed to early syphilis (1). Transmission by sexual contact does not occur during the late latent and tertiary stages of infection. Untreated syphilis in pregnant women can lead to complications during pregnancy and delivery including neonatal death, still birth, blindness, deafness, abnormal bone growth and/or mental retardation.

T. pallidum is usually transmitted sexually through microabrasions in mucosal membranes or skin, and rapidly enters the bloodstream to disseminate to other tissues $(5,6)$. To establish infection, $T$. pallidum adheres to epithelial cells and extracellular matrix components of the skin and mucosa (6). T. pallidum replicates at the site of initial inoculation, inducing a local inflammatory response that results in a painless chancre approximately three to six weeks after initial infection. Within three to eight weeks, the chancre heals, indicating clearance of T. pallidum locally. Once the organism breaches the epidermal layer, multiplication occurs locally, followed by dissemination through the blood vessels and lymphatics. Secondary syphilis results from the multiplication and dissemination of the spirochaetes and can occur up to six months after healing of the primary lesion. This stage can last from several weeks to months and may reoccur in approximately $25 \%$ of untreated patients. It is characterized by a range of clinical symptoms including malaise, headache, lowgrade fever, rash (including on the palms and soles of the feet), and mucous patches in the oral cavity or genital tract. The symptoms of

${ }^{1}$ National Microbiology Laboratory, Winnipeg, Manitoba; ${ }^{2}$ BC Public Health Microbiology and Reference Laboratory, and Department of Pathology and Laboratory Medicine, University of British Columbia, Vancouver, British Columbia; ${ }^{3}$ Ontario Agency for Health Protection and Promotion, Toronto; ${ }^{4}$ McMaster University, Hamilton, Ontario; ${ }^{5}$ Alberta Provincial Laboratory for Public Health, Calgary, Alberta; ${ }^{6} \mathrm{Hopital}$ Dr George Dumont, Moncton, New Brunswick; ${ }^{7}$ Centre for Communicable Diseases and Infection Control, Public Health Agency of Canada, Ottawa, Ontario; ${ }^{8}$ Cadham Provincial Laboratory, and Department of Medical Microbiology $\mathcal{E}$ Infectious Diseases and Department of Immunology, University of Manitoba, Winnipeg, Manitoba; ${ }^{9}$ Division of Pediatric Infectious Diseases, University of Alberta, Edmonton, Alberta; ${ }^{10}$ Saskatchewan Disease Control Laboratory, Regina, Saskatchewan; ${ }^{11}$ Canadian Public Health Laboratory Network, Winnipeg, Manitoba; ${ }^{12}$ Institut national de santé publique du Quebec-LSPQ, Sainte-Anne-de-Bellevue, Quebec; ${ }^{13}$ Division of Infectious Diseases, University of Alberta, Edmonton, Alberta; ${ }^{14}$ Public Health Agency of Canada, Ottawa, Ontario

Correspondence: Dr Raymond Tsang, National Microbiology Laboratory, Public Health Agency of Canada, 1015 Arlington Street, Winnipeg,

Manitoba R3E 3R2. Telephone 204-789-6020, fax 204-789-2018, e-mail raymond.tsang@phac-aspc.gc.ca

Received for publication June 26, 2014. Accepted October 4, 2014

OPEN ACCESS

This open-access article is distributed under the terms of the Creative Commons Attribution Non-Commercial License (CC BY-NC) (http:// creativecommons.org/licenses/by-nc/4.0/), which permits reuse, distribution and reproduction of the article, provided that the original work is properly cited and the reuse is restricted to noncommercial purposes. For commercial reuse, contact support@pulsus.com 
secondary syphilis will resolve with or without treatment. Without treatment, however, the infection will progress to the latent and tertiary stages of syphilis. The latent stage is divided into early (within one year of infection) and late phases. Latency can last for many years and approximately $70 \%$ of untreated patients will remain in this stage for the rest of their lives. The last stage of syphilis, the tertiary stage, is rarely seen today given effective antibiotic therapy. It usually occurs in $15 \%$ to $40 \%$ of untreated individuals, and can occur between five and 40 years after infection (5). In this stage of syphilis, the bacteria invade the central nervous system, eyes, skin, cardiovascular system and other organs.

\section{EPIDEMIOLOGY OF SYPHILIS}

Despite the existence of simple and validated screening tests, effective prevention measures, such as condoms, and effective and relatively cheap treatment options, syphilis remains a global problem, with an estimated 12 million people infected annually (7). The World Health Organization (WHO) estimates that two million pregnant women each year are infected with syphilis globally and that approximately $25 \%$ end in stillbirth or spontaneous abortion (7).

In Canada, infectious syphilis (comprising of the primary, secondary and early latent stages) is notifiable. Based on nationally reported case reports, during the early and mid-1990s, Canada, like other highincome countries, was approaching or achieving its goal to eliminate of endemic transmission of syphilis (8). Since 2000, however, there has been a re-emergence of syphilis in the country, driven, in part, by reported outbreaks among men who have sex with men, although recent reports suggest increased incidence among the heterosexual population. Between 2000 and 2012, the overall reported rate of infectious syphilis has increased by $481 \%$, from 1.84 per 100,000 population to 8.85 per 100,000 population (Figure 1) (9).

\section{PUBLIC HEALTH IMPLICATIONS OF INCREASES IN INFECTIOUS SYPHILIS}

The global increases in the reported prevalence of infectious syphilis is cause for public health concern (10). Syphilis is, in principle, entirely preventable and potentially eradicable because humans are the sole reservoir for this infection. Therefore, investment in syphilis prevention and treatment should result in reduced disease burden and associated costs in the future. In addition, HIV transmission is believed to be facilitated by ulcerative sexually transmitted infections. While the relationship between syphilis and HIV in the context of coinfection is complex, syphilis has been estimated to increase HIV transmission two- to ninefold and HIV acquisition two- to fourfold (11-13). Hence, treatment and prevention of syphilis will likely also reduce HIV transmission in that population. Finally, syphilis is an important public health marker for behavioural risk factors. In the United States, for example, the resurgence of syphilis among men who have sex with men was associated with increases in the number of anonymous sex partners, use of the Internet for meeting sex partners, decreases in condom use and more widespread use of methamphetamine $(14,15)$. Similarly, in the downtown east side of Vancouver (British Columbia), a syphilis outbreak was associated with crack cocaine use and the sex trade (16). Any sustained decline in syphilis will, therefore, need to be accompanied by behavioural changes.

While prevention and treatment are essential for the control of syphilis, diagnosis forms the third critical component in public health programming. In Canada, testing for syphilis has traditionally consisted of initial screening with an inexpensive nontreponemal test and confirmatory testing of the reactive specimen with a more expensive treponemal test. However, since the advent of immunoassays and recombinant $T$. pallidum antigens as screening tools, there have been rapid changes to laboratory testing algorithms for syphilis across Canada. These approaches have introduced complexities in the interpretation of test results and how patients with such results should be managed. In addition, newer tests have become available that allow for rapid, point-of-care testing, and new molecular tests have emerged. Special situations, such as neurosyphilis and congenital syphilis, remain diagnostic challenges. The purpose of the chapters contained in this supplement is to provide guidance on testing for syphilis in Canada.

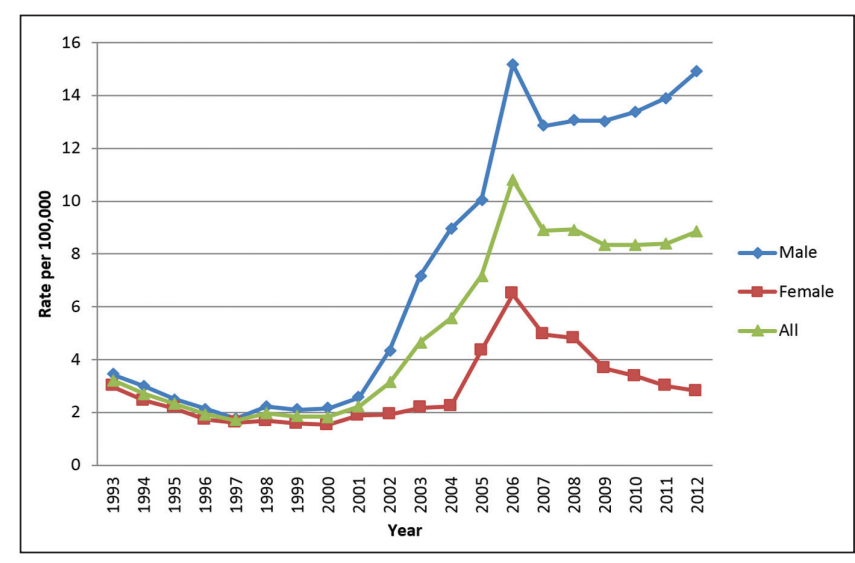

Figure 1) Reported overall and sex-specific rates of infectious syphilis in Canada, 1993 to 2012 (9)

ACKNOWLEDGEMENTS: The authors thank the Canadian Public Health Laboratory Network (CPHLN) for its support and resources in the development of this manuscript, including Secretariat lead Sandra M Radons; the participating laboratories for their contributions to the membership of the CPHLN Syphilis Laboratory Task Group; Dr Joan Robinson for review of the chapter on Congenital Syphilis and Screening in Pregnant Women; and Dr Vanessa Allen for her contribution to a preliminary first draft of the direct detection manuscript.

DISCLOSURES: The authors have no conflicts of interest to declare.

\section{REFERENCES}

1. Hook EW, Marra CM. Acquired syphilis in adults. N Engl J Med 1992;326:1060-9.

2. Antal GM, Lukehart SA, Meheus AZ. The endemic treponematoses. Microbes Infect 2002;4:83-94.

3. Farnsworth N, Rosen T. Endemic treponematosis: Review and update. Clin Dermatol 2006;24:181-90.

4. Fanella S, Kadkhoda K, Shuel M, Tsang R. Local transmission of imported endemic syphilis, Canada, 2011. Emerg Infect Dis 2012;18:1002-4.

5. Singh AE, Romanowski B. Syphilis - A review with emphasis on clinical, epidemiologic and some biologic features. Clin Micro Rev 1999;12:187-209.

6. Ho EL, Lukehart SA. Syphilis: Using modern approaches to understand an old disease. J Clin Invest 2011;121:4584-92.

7. World Health Organization, 2007. The global elimination of congenital syphilis: Rationale and strategy for action. $<$ http:// whqlibdoc.who.int/publications/2007/9789241595858_eng.pdf?ua=1> (Accessed April 24, 2014).

8. Proceedings of the National STD Consensus Meeting, February 1996. National Goals for the Prevention and Control of Sexually Transmitted Diseases in Canada, CCDR 23S6 November 1997.

9. Public Health Agency of Canada, Notifiable Diseases Online (1993 to 2012). <dsol-smed.phac-aspc.gc.ca/dsol-smed/ndis/charts.php> (Accessed June 23, 2014).

10. Doherty L, Fenton KA, Jones J, et al. Syphilis: Old problem, new strategy. BMJ 2002;325:153-6.

11. Greenblatt RM, Lukehart SA, Plummer FA, et al. Genital ulceration as a risk factor for human immunodeficiency virus infection. AIDS 1988;2:47-50.

12. Wasserheit JN. Epidemiological synergy. Interrelationships between human immunodeficiency virus infection and other sexually transmitted diseases. Sex Transm Dis 1992;19:61-77.

13. Royce RA, Sena A, Cates W Jr, et al. Sexual transmission of HIV. N Engl J Med 1997;336:1072-8.

14. Golden MR, Marra CM, Holmes KK. Update on syphilis: Resurgence of an old problem. JAMA 2003;290:1510-4.

15. Wong W, Chaw JK, Kent CK, Klausner JD. Risk factors for early syphilis among gay and bisexual men seen in an STD clinic: San Francisco, 2002-2003. Sex Transm Dis 2005;32:458-63.

16. Patrick DM, Rekart ML, Jolly A, et al. Heterosexual outbreak of infectious syphilis: Epidemiological and ethnographic analysis and implications for control. Sex Transm Infect 2002;78(Suppl 1):i164-9. 


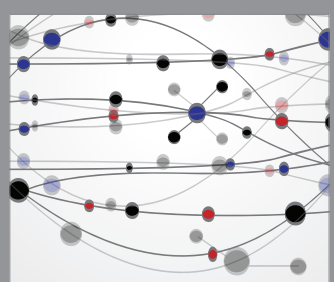

The Scientific World Journal
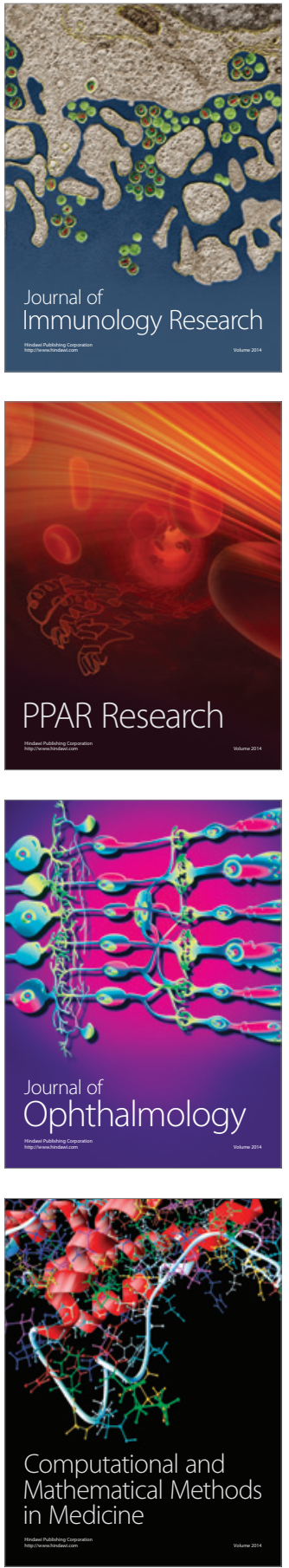

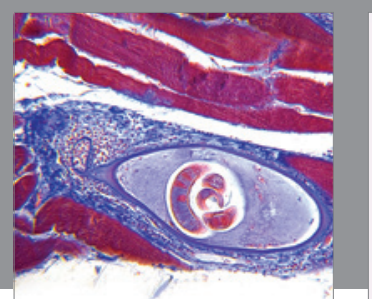

Gastroenterology Research and Practice

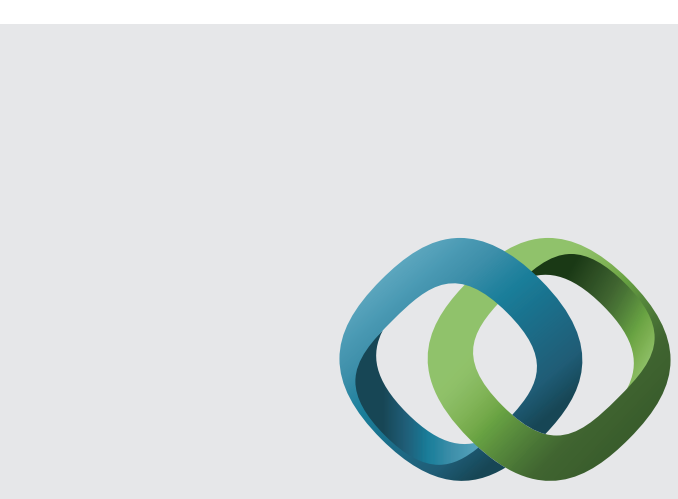

\section{Hindawi}

Submit your manuscripts at

http://www.hindawi.com
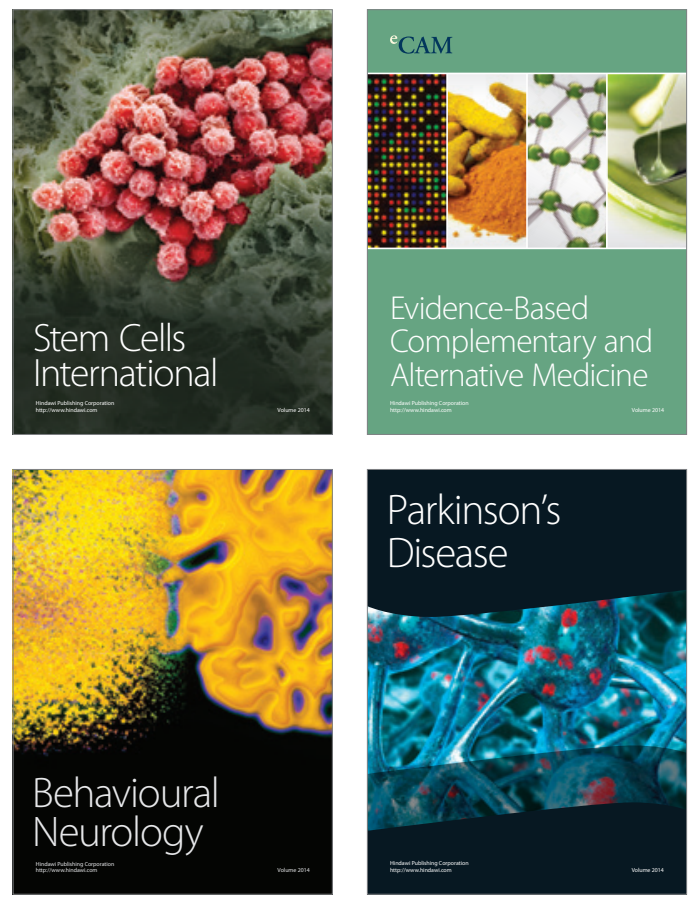
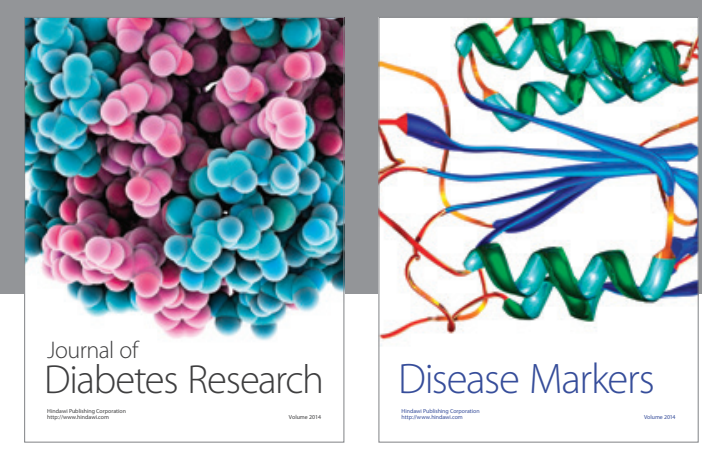

Disease Markers
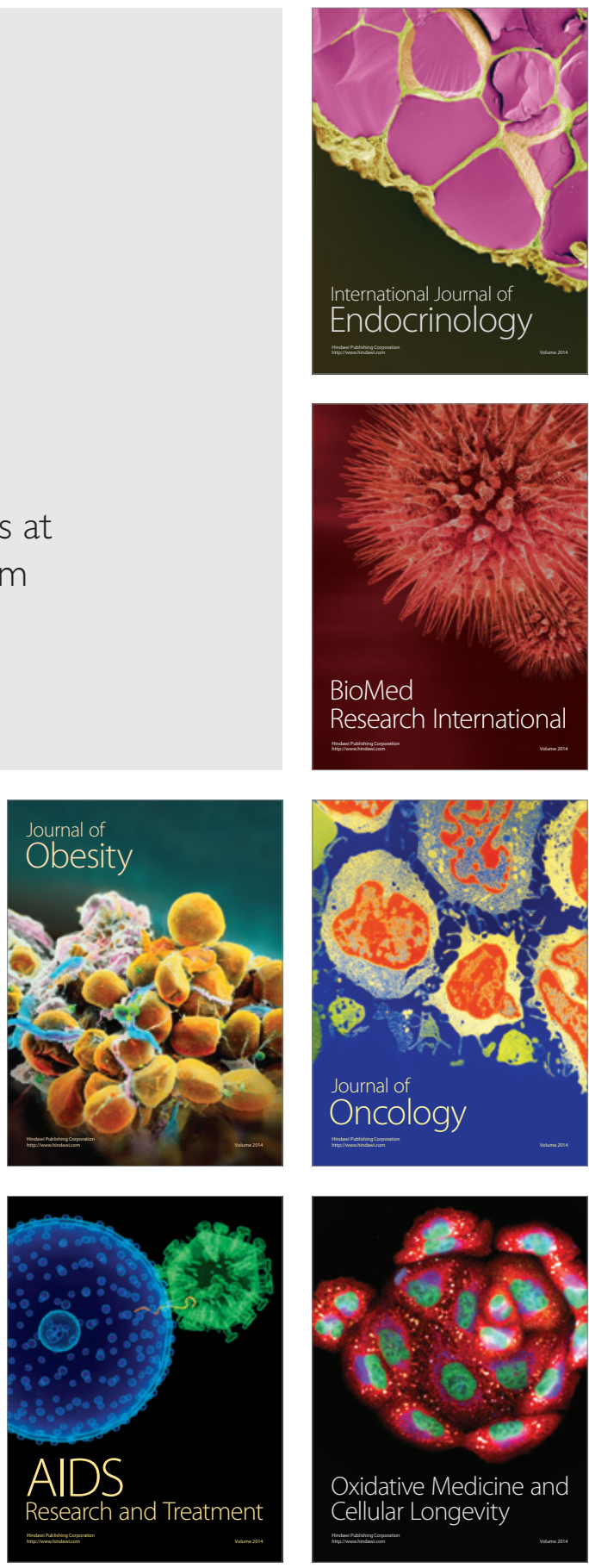